\title{
AC 2010-326: TOWARDS MORE EFFICIENT PRACTICES AND METHODS FOR ABET ACCREDITATION
}

\section{Ivana Milanovic, University of Hartford}

Ivana Milanovic is an Associate Professor of Mechanical Engineering in the College of

Engineering, Technology, and Architecture at the University of Hartford. She received her Ph.D. in Mechanical Engineering from Polytechnic Institute of NYU, NY and M.S. and B.S. from University of Belgrade, Serbia.

\section{Tom Eppes, University of Hartford}

Tom Eppes is an Associate Professor of Electrical and Computer Engineering in the College of Engineering, Technology, and Architecture at the University of Hartford. He holds Bachelor and Master of Science degrees in Electrical Engineering from Texas A\&M University and a Ph.D. in Electrical Engineering from the University of Michigan. 


\title{
Towards More Efficient Practices and Methods for ABET Accreditation
}

\begin{abstract}
For many institutions, maintaining ABET accreditation(s) requires a significant investment of faculty and financial resources. This is especially the case since the Technology Criteria 2000 were introduced requiring a greater emphasis on continuous improvement processes and outcome-based assessment. With each review cycle, the standards for demonstrating compliance are raised; consequently, the effort required to plan, prepare and follow-up on general visits places an increasing burden on programs, departments and colleges. This paper discusses the means, methods and techniques developed to efficiently deploy departmental and program resources on small undergraduate institutions.

Our College maintains nine accreditations with both the Technology and the Engineering Accreditation Commissions of ABET. The following practices have been put into place to maximize productivity: (1) prime movers lead, plan and coordinate the process, (2) standardized templates are employed, (3) deliverables are assigned and shared by faculty, (4) useful content is sourced from all programs and (5) faculty are supported with 'how to' instructions, examples and assessment tools.

Our approach which encompasses process, methods and tools improves resource efficiency within and across departments. For high level materials, a consistent format is essential for strategic plans, continuous improvement, educational objectives, program outcomes and assessment plans. Additional leverage is gained by standardizing documentation of course improvements, capstone projects and faculty development. Common materials that describe cocurricular multidisciplinary activities and shared facilities are prepared and disseminated at the College level. The purpose of this paper is to present the specifics of our approach and lessons learned from the latest general visit along with recommendations for future improvements.
\end{abstract}

\section{Introduction}

Our College is part of a private institution with about 900 students of which 400 are enrolled in undergraduate engineering programs. Bachelor of Science degrees, accredited by the Engineering Accreditation Commission (EAC), are offered in six majors: Acoustical Engineering \& Music (new), Biomedical, Civil, Computer, Electrical and Mechanical Engineering. Within the last 10 years, three of the above programs were accredited for the first time. In addition, three of our five undergraduate engineering technology programs, accredited by the Technology Accreditation Commission (TAC), are offered in the following majors: Architecture, Electronic and Mechanical Engineering Technology. The 11 engineering and engineering technology programs, as well as a Masters program with 150 students, are administered by 4 departments with a combined fulltime faculty of 38 and a professional staff of 5 .

Our experience parallels other institutions in seeking new and better ways to address accreditation and assessment planning ${ }^{1-9}$. Given the level of work required to demonstrate 
program achievement and faced with substantial teaching, research and service loads, program administration must be streamlined. Since continuous improvement and embedded outcome assessment is an integrated effort on the part of faculty, small efficiencies become magnified when applied across the College.

\section{Continuous Improvement}

Over recent accreditation cycles, a set of processes and methodologies have been developed to maximize the organizational efficiency associated with preparing for and conducting general visits. We began by focusing on the high level documents that comprise the continuous improvement process (CIP). These materials describe the constituencies and the feedback mechanisms used to sustain a successful program. The following documents constitute the core CIP materials:

- Missions (university, college, department and program)

- Program strategic plan

- Constituencies

- Program educational objectives (PEOs)

- Program outcomes (POs)

- CIP flowcharts and tables

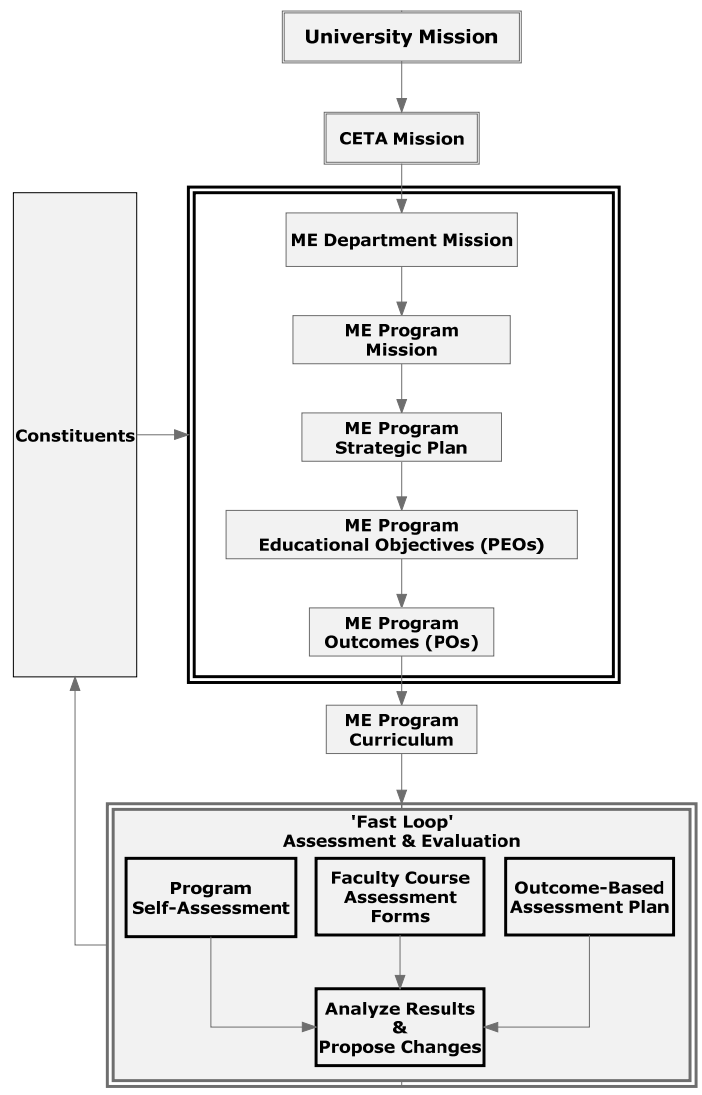

Fig. 1 Flowchart of the ME continuous improvement process 
The same templates are used by all departments with exhibits posted online so faculty and staff can view what has been prepared across the College. Department Chairs and Program Directors serve as prime movers for much of the work and maintain consistency in style and content to harmonize efforts and facilitate communication. We were aided by a wide range of ABET materials published on the web by other institutions, making it easy to find best practices ${ }^{1,3,5}$. Figure 1 shows the CIP flowchart for the Mechanical Engineering (ME) program, and illustrates how the multiple missions and strategic plan support the PEOs and POs.

\section{Program Educational Objectives}

PEOs, developed based on input from the constituencies, describe the 3-5 year career goals that are expected of alumni. PEOs are re-visited and assessed on a six-year cycle unless there is a need to do so sooner. In the most recent assessment cycle, it was found that some PEOs were worded like outcomes and did not appropriately reflect career accomplishments. As a result, changes were made to more accurately state the near term expectations of graduates. Further, alumni surveys revealed that some graduates had chosen a career path outside or tangential to that of their undergraduate program so PEOs were changed to accommodate a broader range of career possibilities.

During each PEO review cycle, input is solicited from the program constituents; however, some are engaged to provide more specific feedback. The key constituents are currently defined as: (1) graduating seniors, (2) alumni, (3) employers and (4) Industry Advisory Board (IAB) members. For each PEO, survey responses are rated on a 1-to-5 scale, and the results are aggregated. A goal of $70 \%$ of responses rating 3 or higher is considered satisfactory. If this goal is not met, faculty search for an underlying cause and take action if needed.

\section{Program Outcomes}

Initially, a unique set of POs were developed to support the PEOs and simultaneously satisfy ABET Criterion 3(a-k) requirements. The resulting POs were distinctive to each program and incorporated one or more Criterion 3(a-k). A series of mapping tables were developed to correlate PEOs, POs and Criterion 3(a-k). However, the resulting matrices overly complicated the outcome assessment process and made it difficult to conclusively document that ABET criteria were being met. Consequently, new POs were introduced that matched one-to-one Criterion 3(a-k). The various missions of the organizational units and the PEOs were reexamined to ensure that the revised POs were aligned. This yielded a greatly simplified assessment process with the flexibility to add additional POs to denote distinctions.

An outcome-based assessment plan (OBAP) with the same structure across all program evaluates $\mathrm{PO}$ achievement. Assessment is either embedded in courses or survey-based with results compared to a pre-established goal. If the goal is not met, the faculty and key constituents develop an appropriate response which may or may not trigger curricular change. Table I shows a subset of courses from the ME curriculum to illustrate some of the embedded assessments. Each PO is typically assessed in 3-4 courses with no course spanning more than 3 Criterion 3(ak). 
Table I Subset of courses used for PO assessment

\begin{tabular}{|l|c|c|c|c|c|c|c|c|c|c|c|c|}
\hline \multirow{2}{*}{$\begin{array}{c}\text { ME Program Required } \\
\text { Course/Course Title }\end{array}$} & \multicolumn{7}{|c|}{ Program Outcomes [Criterion 3(a-k)] } \\
\hline & a & b & c & d & e & f & g & h & i & j & k \\
\hline ES 101 Engineering Freshmen Dialogue & & & & & & $\checkmark$ & $\checkmark$ & & & $\checkmark$ & \\
\hline ES 110 Statics f/E & $\checkmark$ & & & & & & & & & & \\
\hline ES 115 Eng. Computer Applications & & & & & $\checkmark$ & & & & & & $\checkmark$ \\
\hline ES 143 Engineering and Design & & & $\checkmark$ & $\checkmark$ & & & $\checkmark$ & & & & \\
\hline ES 211 Dynamics f/E & & & & & & & & & & & \\
\hline ES 212 Mechanics of Materials f/E & $\checkmark$ & & & & & & & & & & \\
\hline ES 220 Graphic Communication & & & & & & & & & & & $\checkmark$ \\
\hline ES 242 Engineering by Design & & & & $\checkmark$ & & $\checkmark$ & & & & $\checkmark$ & \\
\hline ES 342 Engineering Practice & & & & $\checkmark$ & & $\checkmark$ & & & $\checkmark$ & & \\
\hline ES 440 Automatic Control System Analysis f/E & & & & & $\checkmark$ & & & & & & \\
\hline
\end{tabular}

Table II shows the embedded elements used to assess a single PO in the Electrical Engineering program for communication skills (i.e. Criterion $3 \mathrm{~g}$ ). In this case, assessment is comprised of assignments in 3 courses plus 2 surveys covering both oral and written communication. Outcome data is quantified into 5 levels of achievement which harmonizes exam results, rubric scores and survey responses. A goal of 70\% achievement of level 3 or higher is set, and shortfalls trigger the possibility of action.

Table II Embedded Course \& Survey Assessment Elements

\begin{tabular}{|l|c|c|c|c|c|}
\hline Program Outcome & ES 143 & ES 242 & ECE 483 & Grad Srs. & Alumni \\
\hline \multirow{2}{*}{$\begin{array}{l}\text { an ability to communicate } \\
\text { effectively }\end{array}$} & $\begin{array}{c}\text { Oral } \\
\text { presentation }\end{array}$ & $\begin{array}{c}\text { Oral } \\
\text { presentation }\end{array}$ & $\begin{array}{c}\text { Oral } \\
\text { presentation }\end{array}$ & Survey & Survey \\
\cline { 2 - 6 } & $\begin{array}{l}\text { Written } \\
\text { Report }\end{array}$ & $\begin{array}{c}\text { Written } \\
\text { Report }\end{array}$ & $\begin{array}{c}\text { Written } \\
\text { Report }\end{array}$ & Survey & Survey \\
\hline
\end{tabular}

\section{Managing Change}

Change proposals for all programs originate from several sources and/or loops within the CIP and broadly speaking there are two cycle times, fast and slow, as shown in Fig. 1. The 'fast loop' consists of three parallel activities: (1) faculty course assessment (2) OBAP and (3) program selfassessment. At semester's end, each instructor completes a course assessment that summarizes the effectiveness in achieving the desired outcomes and makes recommendations for the future. These change proposals are not formally reviewed by the Department as a whole, but rather by the faculty who teach in that area or specialty. Some typical examples include new laboratory experiments, updated teaching and learning materials and enhanced lecture presentation content. OBAP, a second source of change, is addressed at the annual faculty retreat. Student PO achievement versus goals is reviewed, and an action plan developed. In many cases, changes 
within a single course are sufficient to address an issue. Occasionally, the root cause may lie in a formative course that is part of a sequence, e.g. math, science or design, leading to multiple course improvements. The third source is program self-assessment which summarizes the actions and results for Criteria 1-9 and is supplemental to the activities described above.

PEO assessment is part of the 'slow loop' where changes typically occur over a period of years. For example, changes to the University, College, Department and Program mission statements and strategic plans may impact one or more PEOs. Assessment and evaluation within the 'fast loop' may trigger the need for alterations of one or more PEOs. The need for change may also be driven by PEO constituency feedback, e.g. alumni and employer surveys. Similar to the process used in PO assessment, results that are below goal trigger potential action. Issues, findings and recommendations are reviewed at the Department retreat. Some recent examples include: (1) modification of PEO and PO statements, (2) new or modified courses, (3) inclusion of emerging technologies and (4) different emphasis of an existing topic. For change proposals, the programs employ and share the same templates, internal processes and review cycles.

Program changes take place at three levels - general education (including mathematics and basic sciences), evolutionary program specific changes, and comprehensive program reviews. Data from alumni surveys, graduating senior surveys, faculty course assessment reviews and OBAP findings are collected and reviewed each academic year. Comprehensive program reviews are typically performed on a 6 year cycle and involve evaluating a broad data set, identifying trends in the discipline and employment opportunities, recommendations from the National Academy of Engineering on trends, comparison with programs in other universities, and consideration of the needs and resources of the Department. Ensuing recommendations are presented to the IAB and the faculty.

\section{Faculty Survival Kits}

Faculty supply a variety of materials for self-studies including: CVs, course syllabi, professional development plans/activities and course assessments/improvements. In addition, faculty are integral to the assessment process and the collection of display materials for the visit. To streamline preparation and ensure consistent results, a faculty survival kit (FSK) was developed. FSK serves as a 'how to' guide with instructions on content as well as formatting. Templates and samples are included, and online access makes it easy to download and use. A general-purpose FSK was first created then modified to suit the needs of each program. The FSK table of contents is shown below:

- Faculty Documentation

- Sample CV

- CV Template

○ Short and Long Term Professional Development Plan

- Self-Study Tables

- Table 6-1. Faculty Workload Summary

$\circ$ Table 6-2. Faculty Analysis

- ABET Course Notebook Contents

- Sample Course Syllabus

- Course Assessment Form 
- Record of Course Updates

- Sample 1 - Course Update Rubric

- Sample 2 - Course Changes

- Program Assessment Materials

- Program Educational Objectives

- Curriculum Grid

- Program Outcomes

- Documentation Responsibilities

- Program Outcome-based Assessment Plans

- Assessment Forms \& Tools

○ Outcome-Based Assessment Forms \& Rubrics

- Numerical Grade Distribution

- Team Skills Rubric

- Communication Skills Rubric

- Capstone Design Rubric

- Rubric Skills Distribution

FSK is an efficient means to disseminate templates, completed samples, assessment tools and instructions for self-study input as well as display material preparation. Faculty and administrative personnel save time, and meetings are not burdened with documentation-related topics.

\section{Supplemental Content}

During self-study preparation, several sources of content were discovered that may have gone unnoticed had the need for efficiency not been a priority. Valuable material may be pedagogical publications by faculty ${ }^{10-14}$. For example, one paper ${ }^{13}$ described the College's senior capstone design courses and the trade-offs that have been considered over time. Other work ${ }^{11,14}$ outlined an internal initiative to educate and encourage students to pursue program minors, associate degrees and technical concentrations. A third paper ${ }^{12}$ detailed the evolution of a second-year professional course in interdisciplinary design. Tapping into pedagogical publications yielded a rich perspective on the rationale and benefits of recent curricular improvements.

\section{Conclusions}

In a primarily teaching institution with 11 accredited programs, the need to maximize productively among the faculty, staff and administrative personnel is imperative. Approaching the second ABET general visit relative to the new continuous improvement criteria, we decided to re-structure our approach for self-study preparation and site visit readiness to gain efficiencies. Significant efficiencies were obtained in time and effort as well as the quality of materials compared to the previous cycle. These improvements are attributed to the following practices: (1) rely on prime movers to play an early leading role, (2) clearly set responsibilities and expectations, (3) standardize processes and procedures across programs and departments, (4) incorporate useful content that may already be on hand and (5) support faculty with 'how to' instructions, templates, samples and assessment tools. 


\section{Bibliography}

1. Rodriguez-Marek, E., Koh, M. and Talarico, C., "Connecting the Dots in Assessment: From Course Student Learning Objectives to Educational Program Outcomes to ABET Assessment," ASEE Annual Conference Proceedings, Pittsburg, PA, Paper AC-2008-316.

2. Shrycok, K. and Reed, H., "Preparing Effectively For ABET Accreditation: What Does It All Mean?, ASEE Annual Conference Proceedings, Pittsburg, PA, Paper AC-2008-2403.

3. Christie, B. and Cooney, E., "Meet the ABET 'Student Work Sample' Requirements: Document Student Learning,” ASEE Annual Conference Proceedings, Austin, TX, Paper AC-2009-188.

4. Welch, R., "Surviving ABET Under the New Criteria - From the Eyes of New Chair in a New CE Department," ASEE Annual Conference Proceedings, Austin, TX, Paper AC-2009-733.

5. Abel, K., "Preparing an ABET Self-Study Continuous Improvement the Second Time Around," ASEE Annual Conference Proceedings, Austin, TX, Paper AC-2009-208.

6. Bannerot R., “ Addressing Most of ABET Criterion 3 Issues First in an Early Design Class,' Proceedings of the ASME 2009 Mechanical Engineering Conference and Exposition, Lake Buena Vista, FL, Paper IMECE-200912474.

7. Morales, J. C., "Implementing a Robust, Yet Straightforward, Direct Assessment Process that Engages 100\% of the Faculty," Proceedings of the ASME 2009 Mechanical Engineering Conference and Exposition, Lake Buena Vista, FL, Paper IMECE-2009-12502.

8. Bryan, A., Brackin, P., and Sanders, W., "Evaluating Lifelong Learning," Proceedings of the ASME 2009 Mechanical Engineering Conference and Exposition, Lake Buena Vista, FL, Paper IMECE-2009-12638.

9. Hodge, B.K., "Enhancing Students' Energy Engineering Skills by Embedding Topics in Homework Exercises," Proceedings of the ASME 2009 Mechanical Engineering Conference and Exposition, Lake Buena Vista, FL, Paper IMECE-2009-13250.

10. Milanovic, I. M. and Eppes, T. A., 'Modular, Adaptable, and Reusable Approach to Thermal-Fluids Outwitting the Norms (MARATHON),' 2008 ASEE Annual Conference Proceedings, Pittsburgh, PA, Paper 2008-440.

11. Eppes, T. A., Milanovic, I. M., and Girouard, J., 'An Integrative Approach to Undergraduate and Graduate Change,' 2008 ASEE Annual Conference, Pittsburgh, Paper 2008-446.

12. Pines, D. and Alnajjar, H., "Evolution of an Interdisciplinary Sophomore Design Course at the University of Hartford," ASEE National Conference Proceedings, Pittsburgh, PA, Paper 2008-1707.

13. Milanovic, I. M., Eppes, T. A., 'Capstone Projects for Engineering Technology: Issues, Benefits, and Tradeoffs,' 2009 ASEE Annual Conference Proceedings, Austin, TX, Paper 2009-30.

14. Eppes, T. A., Milanovic, I. M., and Girouard, J., 'Creating Value-Oriented Curricular Models,' Conference Proceedings of the International Journal of Arts and Sciences, 2009, Gozo, Malta, MAL133-EPP. 